Hongwei Wang

Gang Ma

Liping Sun

Kaiye $\mathrm{Hu}$

http://dx.doi.org/10.21278/brod68403

ISSN 0007-215X

eISSN 1845-5859

\title{
MODEL TEST AND COUPLED DYNAMIC ANALYSIS OF A DEEPWATER FPSO WITH INTERNAL TURRET MOORING SYSTEM
}

UDC 629.5.018.1-8: 629.5.028-7: 629.563: 629.5.015.2

Original scientific paper

\begin{abstract}
Summary
Model test is an effective way to verify numerical dynamic analysis of floating system. The diffraction and radiation analysis is carried out in frequency domain based on potential theory to predict motion response of rigid platform. The quasi static and dynamic methods are usually adopted to simulate mooring system, which determines if the whole system is coupled within the analysis. Here model tests are performed to indicate the accuracy of potential theory and quasi static and dynamic methods for the whole system. A FPSO is tested under regular waves to find its RAO. The FPSO with internal turret mooring system under irregular wave, wind and current are also studied in the deepwater basin of Harbin Engineering University. The results are compared between the model test and numerical models, which show the model test results agree well with the coupled numerical model, while the maximum mooring tensions are under estimated in quasi static analysis.
\end{abstract}

Key words: FPSO; model test; mooring; dynamic; coupled

\section{Introduction}

It is important and challengeable to accurately predict the motion response and associated mooring forces for a deepwater floating structure. The dynamic coupling analysis is recognized as the most reliable numerical method presently, and model test is still regarded to be effective verify the numerical simulation. Studies on different cases have been carried out by many researchers in this field.

Dynamic coupled method was first proposed to analyse the large amplitude motion of tension leg platform by Paulling and Webster [1]. It was believed that the mass and fluid forces on tendons were comparable with those from the platform, and the dynamic tendon characteristics were essential for prediction of loads and response of TLP. It was also proved with experiments results by Abyn et al. [2]. Ormberg and Larsen [3] illustrated the distinction between no-coupled and coupled analysis. After performing numerical simulations and model test for different cases, the traditional separated approach was found to be severely inaccurate, especially in deep water. Hull/mooring/riser coupled dynamics analysis of a turret-moored 
FPSO was conducted by Tahar and Kim [4], and compared with experimental results from MARIN. The hydrodynamic contribution was analyzed and assessed respectively in the viscous damping, second-order quadratic transfer functions, and yaw-angle dependent wave forces and hydrodynamic coefficients. Luo et al. [5] presented that for deepwater applications, the mooring lines and risers could significantly affect the response of platforms. The noncoupled, coupled to slow drift motions and fully coupled methods were described in detail.

Different methods are attempted to solve the issues. Time and frequency domain coupled analysis of deepwater floating systems were carried out and compared by Low and Langley [6-7]. The frequency domain approach was verified to be accurate when geometric nonlinearity was not prevalent. A hybrid time/frequency domain approach was also developed and indicated that it was nearly as accurate as fully coupled time domain analysis even for significant coupling and nonlinear effects, but required only one-tenth of the computational time. Tahar and Kim [8] developed a numerical tool for the coupled dynamic analysis of a deepwater floating platform with polyester mooring lines, which considered the relatively large elongation and nonlinear stress strain relationships in polyester fibres. The dynamic responses of mooring lines are also important to include nonlinear inertial forces and drag forces in the couple analysis [9-11]. Zhang et al. [12] presented a comparison of numerical simulations and model tests for a new cell-truss SPAR. The numerical simulations were conducted with frequency-domain analysis, time-domain semi-coupled and fully-coupled analysis. It was found that neither numerical simulation nor model test could perform very well. Jing et al. [13] developed an asynchronous coupling method with MLTSIM and RodDyn, which allowed for a fast simulation of very complex problem. Ma et al. [14] also proposed an asynchronous coupling model and dynamic coupled analysis model for a turretmoored FPSO, and the numerical results had good agreement with model test. Yang et al. [15] developed a full time-domain analysis program and it was applied to a truss spar, which gave reliable prediction of platform response both in the wave-frequency and low-frequency ranges. Fully coupled dynamic analysis to a FPSO system was conducted by Ji et al. [16], the force nonlinearity, mooring nonlinearity, motion nonlinearity were included in the numerical model, but the non-collinear environmental loads were not considered. The results were compared between multi bodies and single body, and the feasibility of the designed system was confirmed. Qiao et al. [17] analysed the global responses analysis for an innovative deep draft multi-spar platform, three different types of the mooring system are considered, namely a catenary, a semi-taut and a taut mooring system with numerical coupling method. The effect of buoys within mooring line was investigated to show that the additional buoy in the mooring line may cause larger surge motion [18].

As described above, how to predict the response of a platform precisely depends on the type of platform, working depth, mooring lines and analysis methods. Uncertainties still exist both for numerical simulations and model tests. Further investigations are still needed. In this paper, numerical simulations and model tests of a FPSO mooring system in $914 \mathrm{~m}$ water depth are discussed in detail, and significative conclusions can be found after comparisons with each other.

\section{Hydrodynamic Analysis of FPSO under Regular Waves}

The purpose of numerical simulations and model tests of FPSO under regular waves is to obtain the FPSO motions, forces and response amplitude operators (RAOs). The results are relatively reliable and can be the base for calculation of FPSO under irregular waves based on linear superposition theory. 
The FPSO studied is a 240,000 DWT tanker working in $914 \mathrm{~m}$ water depth, its particulars are given in Table 1. Both numerical simulation and model tests are performed, and comparisons of them are discussed.

Table 1 Main parameters of FPSO

\begin{tabular}{|l|l|}
\hline Length between perpendiculars $(\mathrm{m})$ & 310.00 \\
\hline Breadth $(\mathrm{m})$ & 47.17 \\
\hline Depth $(\mathrm{m})$ & 28.04 \\
\hline Draught $(\mathrm{m})$ & 18.90 \\
\hline Displacement $(\mathrm{t})$ & 240869.00 \\
\hline Centre of gravity forward of station 0 (m) & 161.60 \\
\hline Centre of gravity above keel $(\mathrm{m})$ & 13.32 \\
\hline Turret position behind Fpp $(\mathrm{m})$ & 63.55 \\
\hline
\end{tabular}

\subsection{Diffraction and Radiation Analysis of FPSO}

The diffraction and radiation analysis is carried out in frequency domain with 3D potential theory to get the response of FPSO under a series of regular waves. The set of linear equations with frequency dependent coefficients for 6-DOF rigid body motions can be stated in matrix as followed:

$$
\left(\mathbf{M}_{S}+\mathbf{M}_{a}\right) \ddot{x}+\mathbf{C} \dot{x}+\mathbf{K} x=\mathbf{F}
$$

in which $\mathbf{M}_{S}$ is mass matrix of FPSO; $\mathbf{M}_{a}$ is added mass matrix; $\mathbf{C}$ is damping matrix; $\mathbf{K}$ is stiffness matrix; $\mathbf{F}$ is the 1st order wave forces acting on FPSO (per unit wave amplitude); $x$ is the response motions.

The mean second order wave drift forces are calculated with the near-field solution. The forces on FPSO in the horizontal and vertical planes are calculated based on the method of direct integration of pressure acting on the wetted surface of the body. The expression for the evaluation of the second order mean wave drift force $F_{\text {wave }}^{(2)}$ and moment $M_{\text {wave }}^{(2)}$ can be written as follows:

$$
\begin{gathered}
F_{\text {wave }}^{(2)}=-\oint_{W L} 0.5 \rho \mathrm{g} \zeta_{r}^{2} \vec{n} d l+\iint_{S_{0}} 0.5 \rho|\nabla \varphi|^{2} \vec{n} d S \\
+\iint_{S_{0}} \rho\left(X \cdot \nabla \frac{\partial \varphi}{\partial t}\right) \vec{n} d S+M_{s} \mathbf{R} \cdot \ddot{X}_{g} \\
M_{\text {wave }}^{(2)}=-\int_{W L} 0.5 \rho \mathrm{g} \zeta_{r}^{2}(\vec{x} \times \vec{n}) d l+\iint_{S_{0}} 0.5 \rho|\nabla \varphi|^{2}(\vec{x} \times \vec{n}) d S \\
+\iint_{S_{0}} \rho\left(X \cdot \nabla \frac{\partial \varphi}{\partial t}\right)(\vec{x} \times \vec{n}) d S+\mathbf{I}_{s} \mathbf{R} \cdot \ddot{X}_{g}
\end{gathered}
$$

in which, $W L$ stands for water line along the structure surface; $\zeta_{r}$ is the relative wave surface elevation; $S_{0}$ is the structure wetted surface; $X$ is the motion at structure surface; $M_{s}$ is the structure mass; $\mathbf{I}_{s}$ is the matrix of structure inertia moment; $\mathbf{R}$ is the structure rotation matrix; $\ddot{X}_{g}$ is the structure CoG acceleration vector.

The numerical simulations of FPSO under a series of regular waves over a pertinent range of periods and directions are carried out by program ANSYS AQWA. The model of FPSO and the definition of coordinate system is in Fig.1. 


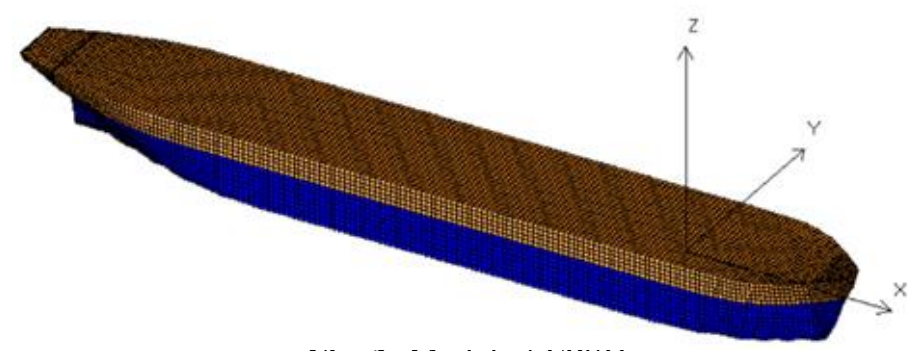

Fig. I Model of HYSU

\subsection{Model Tests of FPSO in HEU basin}

Model tests of FPSO are carried out in the deepwater basin of Harbin Engineering University (HEU). The dimension of HEU basin is $50 \mathrm{~m} \times 30 \mathrm{~m} \times 10 \mathrm{~m}$, the model scale is 1:92, the FPSO model after calibration is in Fig.2. The wave directions are $90^{\circ}, 135^{\circ}$ and $180^{\circ}$.

The layouts of the FPSO are changed to avoid the complexity for the wave maker to adjust wave directions. Four mooring lines are horizontally connected with FPSO to restrain its slow drift motions, but the wave frequency motions are not influenced. The layouts of FPSO in $135^{\circ}$ and $180^{\circ}$ wave directions are demonstrated in Fig.3. The line lengths are designed according to different cases, and the stiffness of the four springs in every case should be the same, and should not lead to resonance of the system.

Appropriate wave periods and wave heights are determined before model tests to ensure the wide ranges of wave frequencies. In addition, the wave slopes are controlled between 0.018 and 0.032 , so the wave heights will have little influence on the RAOs. According to the above factors and the capacity of wave maker, 10 regular waves are selected for model tests and listed in Table 2.



Fig. 2 FPSO model after calibration
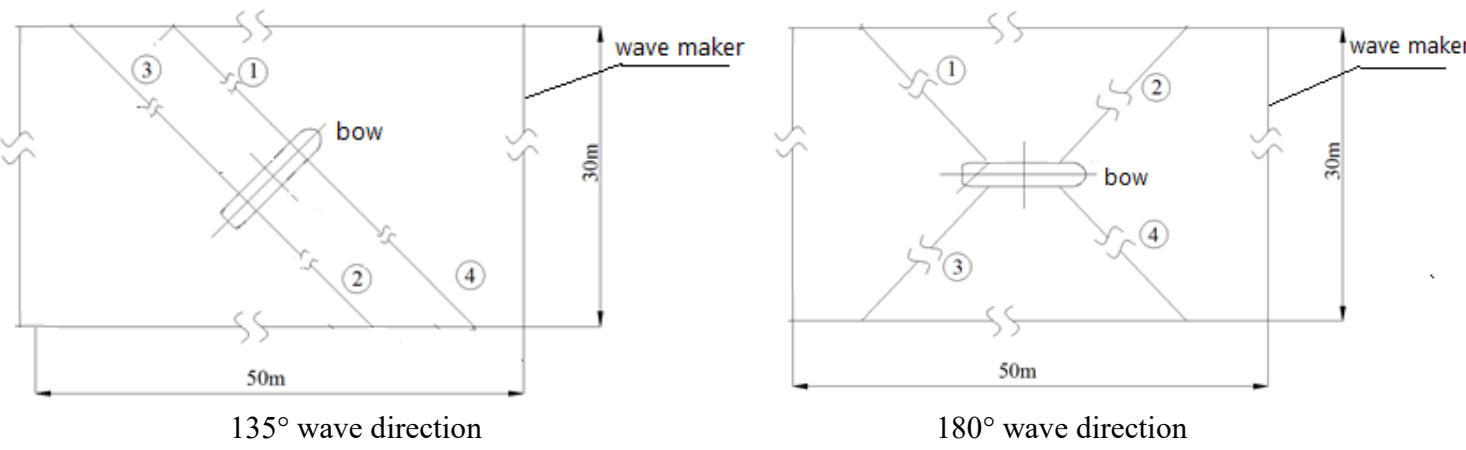

Fig. 3 Schematic plot of FPSO in the basin 
Table 2 Test cases under regular waves

\begin{tabular}{|c|c|c|}
\hline Wave period $(\mathrm{s})$ & Wave height $(\mathrm{m})$ & Wave slope \\
\hline 17.95 & 8.92 & 0.018 \\
\hline 15.71 & 7.26 & 0.019 \\
\hline 13.96 & 7.39 & 0.024 \\
\hline 12.57 & 5.48 & 0.022 \\
\hline 12.09 & 5.97 & 0.026 \\
\hline 11.42 & 4.83 & 0.024 \\
\hline 10.47 & 4.89 & 0.029 \\
\hline 9.67 & 3.76 & 0.026 \\
\hline 8.98 & 3.83 & 0.030 \\
\hline 7.85 & 3.10 & 0.032 \\
\hline
\end{tabular}

\subsection{Comparison of results}

The representative RAO results are compared between the model tests and numerical simulations as listed in Fig.4. It is found that they can agree well with each other in most cases, but some discrepancies still exist at some points. For the roll RAO in $90^{\circ}$, the model test result is lower than the numerical result at the point of resonant frequency, and the possible reason is that the viscosity is not considered in the linear theory of AQWA. Then additional linear roll damping is added to the hydrodynamic model, and the results can agree well with the test results except for the small phase difference. For the yaw RAO in $90^{\circ}$, there are great differences too. The reason may be the small deviation of the bow of FPSO in the basin and then the wave forces are different. But since the yaw RAO is not large, the influence is acceptable. It shows the results of numerical simulations and model tests are complementary and can verify each other, and it is a good base for further analysis of FPSO mooring system.
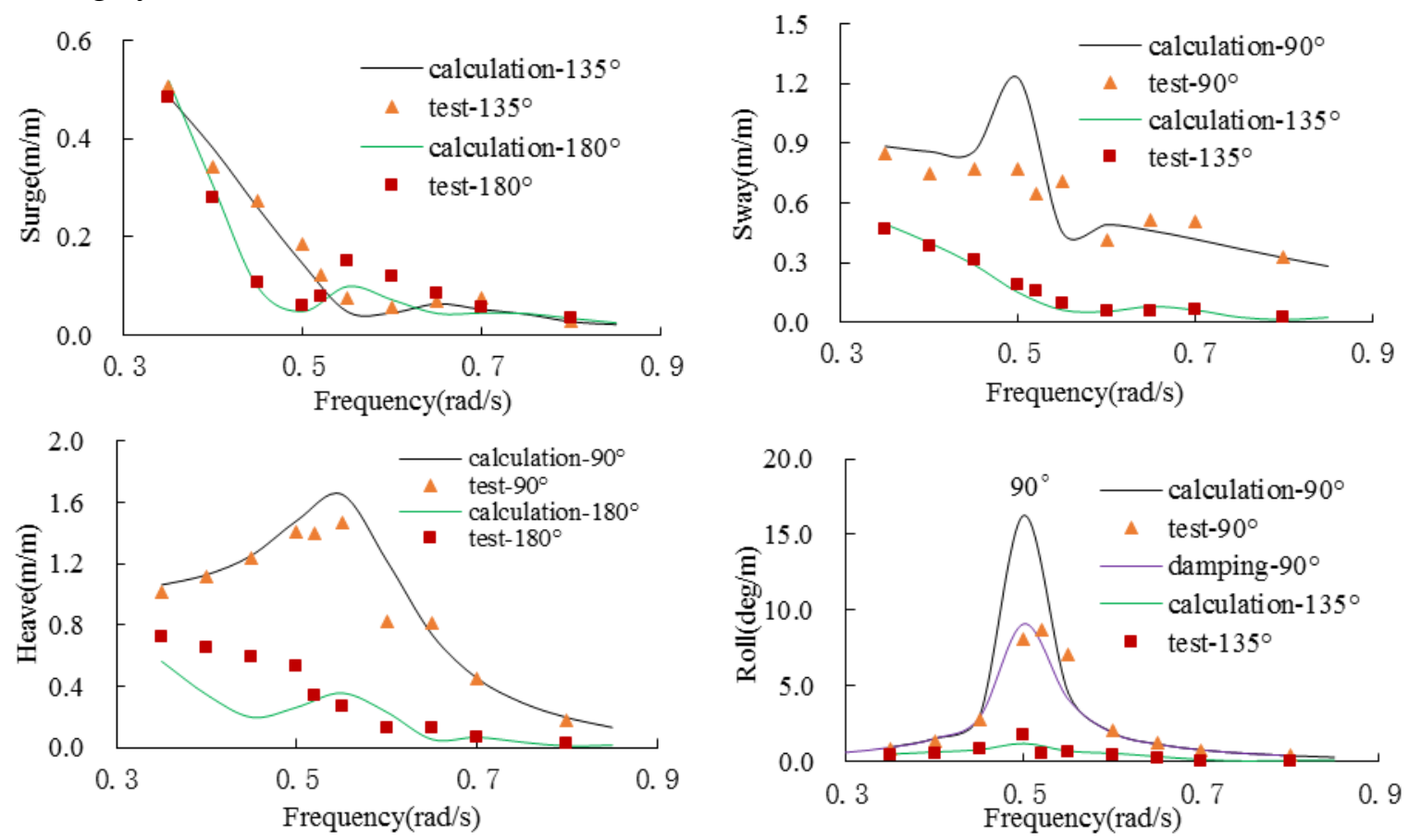

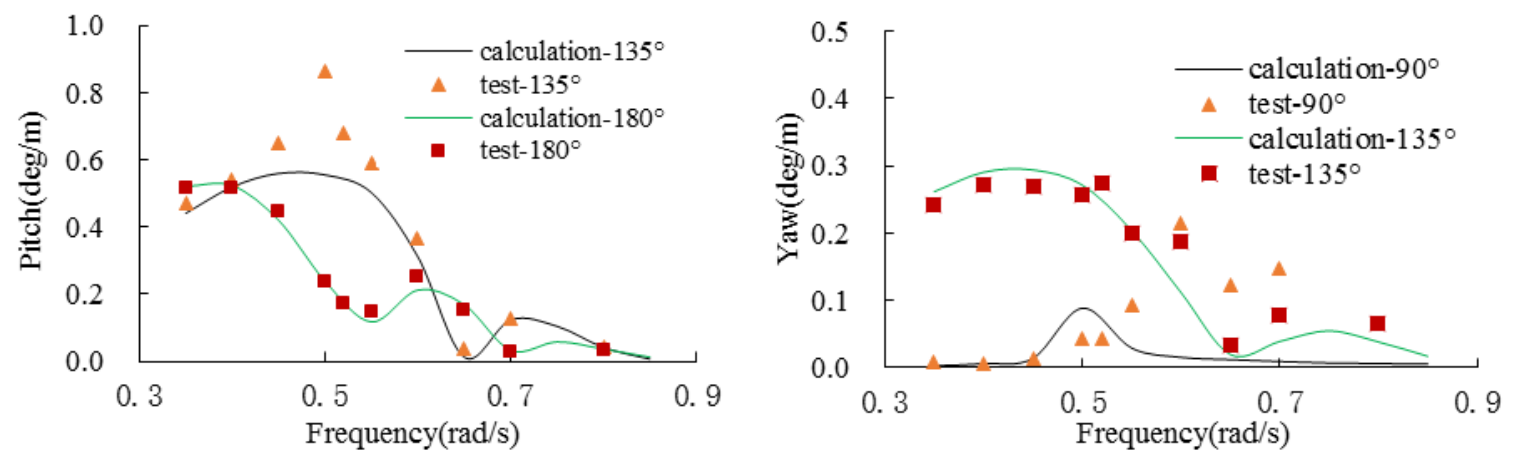

Fig. 4 Comparison of FPSO RAO

\section{Response of FPSO under Irregular waves}

\subsection{FPSO internal turret mooring system}

The FPSO is internal turret moored by 12 identical catenary mooring lines, which are grouped into 4 bundles, containing 3 lines respectively. Each line is made up of 3 segments as chain, wire rope and chain. The parameters of mooring lines are presented in Table 3 . The layout of mooring system is given in Fig.5, where 1 12 represents mooring lines.

The working condition of FPSO is a 100-year extreme hurricane environment in Gulf of Mexico, and the details are given in Table 4.

Table 3 Parameters of mooring lines

\begin{tabular}{|l|c|c|c|c|c|}
\hline \multicolumn{1}{|c|}{ Line } & $\begin{array}{c}\text { Length } \\
(\mathrm{m})\end{array}$ & $\begin{array}{c}\text { Mass in } \\
\text { Water }(\mathrm{kg} / \mathrm{m})\end{array}$ & $\begin{array}{c}\text { EA } \\
(\mathrm{MN})\end{array}$ & $\begin{array}{c}\text { Diameter } \\
(\mathrm{mm})\end{array}$ & $\begin{array}{c}\text { Pretension } \\
(\mathrm{MN})\end{array}$ \\
\hline Top chain & 45.7 & 140.7 & 794 & 89 & \multirow{2}{*}{1.2} \\
\cline { 1 - 4 } Middle wire & 914.4 & 140.7 & 794 & 89 & \\
\hline Bottom chain & 914.4 & 140.7 & 794 & 89 & \\
\hline
\end{tabular}

Table 4 Environmental condition

\begin{tabular}{|l|l|}
\hline Significant wave height $\mathrm{Hs}(\mathrm{m})$ & 12.16 \\
\hline Peak period Tp(s) & 14.0 \\
\hline Wave spectra type & $\mathrm{JONSWAP}(\gamma=2.5)$ \\
\hline Wave direction $(\mathrm{deg})$ & 180 \\
\hline Wind speed(m/s) & 41.12 \\
\hline Wind direction $(\mathrm{deg})$ & 210 \\
\hline Current speed $(\mathrm{m} / \mathrm{s})$ & 1.07 \\
\hline Current direction $(\mathrm{deg})$ & 150 \\
\hline
\end{tabular}




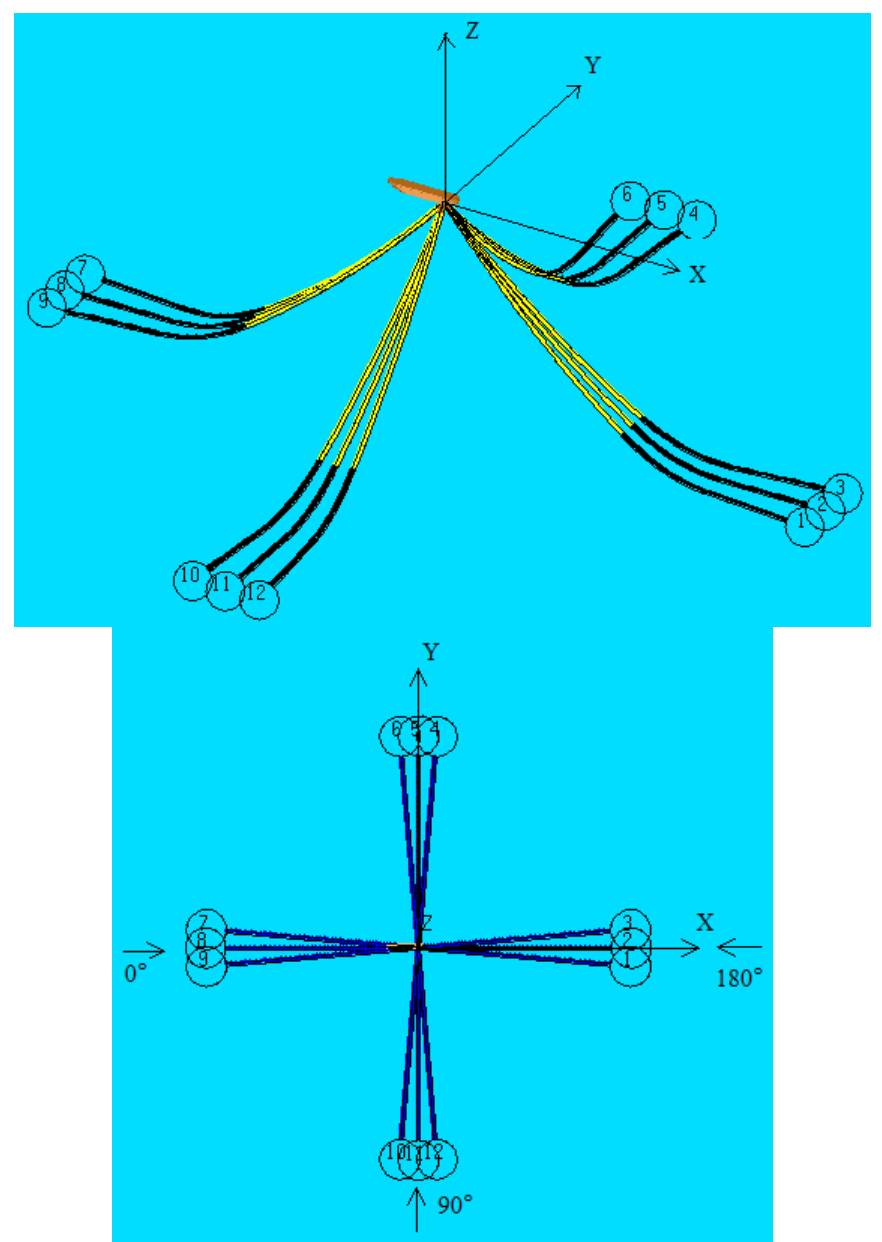

Fig. 5 Layout of FPSO mooring system

\subsection{Coupled analysis of FPSO mooring system}

The motion simulation is performed for the FPSO with its mooring lines by program ANSYS AQWA in time domain, while the vessel slow drift motion and the effect of the mooring system are fully coupled. The equation of motion for the FPSO in 6-DOF is:

$$
\left(\mathbf{M}_{S}+\mathbf{M}_{a}\right) \ddot{x}(t)+\mathbf{C} \dot{x}(t)+\mathbf{K} x(t)=F_{s}+F_{w s}+F_{w f}+F_{s d}+F_{\text {wind }}+F_{\text {current }}+F_{\text {mooring }}
$$

in which $F_{s}, F_{w s}, F_{w f}, F_{s d}, F_{\text {wind }}, F_{\text {current }}, F_{\text {mooring }}$ are static force, mean wave drift force, wave frequency force, slow wave drift force, wind force, current force and mooring force respectively.

The first and second order wave forces are derived from the database calculated in the preceding diffraction and radiation analysis. The slow varying wave drift force is calculated for the horizontal motions only and is based on Newman's approximation [19]. The equation can be written as:

$$
\begin{gathered}
F_{s d}(t)=\sum_{i=1}^{N S P L} \sum_{j=1}^{N S P L} P_{i j}^{-} \cos \left[-\left(\omega_{i}-\omega_{j}\right) t+\left(\varepsilon_{i}-\varepsilon_{j}\right)\right] \\
P_{i j}^{-}=\frac{1}{2} a_{i} a_{j}\left(\frac{P_{i i}^{-}}{a_{i}^{2}}+\frac{P_{j j}^{-}}{a_{j}^{2}}\right)
\end{gathered}
$$

in which $P_{i j}$ is the in-phase component of the time independent transfer function; $\omega_{i}, \omega_{j}$ are the frequencies of each pair of wave components; $a_{i}, a_{j}$ are the amplitudes of the wave 
components; $\varepsilon_{i}, \varepsilon_{j}$ are random phase angles; NSPL is the number of frequency components adopted to represent the wave spectrum.

The convolution of added mass and damping from frequency domain to time domain is adopted in the calculation of radiation forces, which uses the actual structure motion instead of RAOs and do not require RAOs of the vessel. The motion responses are determined by

$$
\left[\mathbf{M}_{S}+\mathbf{M}_{a}(\infty)\right] \ddot{x}(t)+\mathbf{K} x(t)+\int_{0}^{t} \mathbf{h}(t-\tau) \ddot{x}(\tau) d \tau=F(t)
$$

in which $\mathbf{M}_{a}(\infty)$ is the added mass at infinite frequency, $F(t)$ is the total external forces, $\mathbf{h}(t)$ is the acceleration convolution integral function matrix.

The catenary theory is selected to simulate the quasi static characteristics of mooring lines, while the lumped mass method is used to simulate the dynamic characteristics of mooring lines. In the quasi static analysis, vertical motions and dynamic effects associated with mass, damping and fluid acceleration on the mooring line are neglected. In the dynamic analysis, all nonlinear characteristics can be modelled including line stretch, line geometry, fluid loading, and sea bottom effects.

In this study, the mooring lines are not coupled with the FPSO's wave frequency motions because their contributions to such motions are often negligible since the FPSO's inertia properties are an order of magnitude higher than those of the mooring lines.

The wind and current drag coefficients are obtained from report of OCIMF [20], the steady forces and moments are applied on the FPSO with equations from report of OCIMF.

\subsection{Model Test in HEU basin}

Model test of the FPSO mooring system is carried out in HEU basin. The $10 \mathrm{~m}$ basin depth can accommodate to the full system in $914 \mathrm{~m}$. However, the horizontal distance of the basin is not long enough to accommodate to the lateral lines. Therefore, the lines in transverse direction (Line $4,5,6,10,11,12)$ have to be equivalently truncated. The truncation principle is to keep the line weight, stiffness, and static characteristics consistent with the un-truncated system [21-22]. Only the bottom chains are truncated, the middle wire rope and top chain are unchanged. Considering the actual facilities in the basin, the span in width of mooring lines are restricted to $28 \mathrm{~m}$, and after truncation design, the parameters are in Table 5, and the horizontal layout of the mooring lines are in Fig.6. The turret and mooring line models after calibration are in Fig.7. The parameters of the line model after adjustment are presented in Table 6, and there are still some differences within the theory requirements, which can be acceptable.

Since there is no false table in the basin for anchoring the mooring lines, 4 anchor bases with sufficient weights are designed to fix the mooring lines, which can keep them stable enough. There are 3 anchor points in every base and the distance among them is set according to actual requirements. The bases are lowered to the pre-calculated bottom positions by the crane.

There are no wind and current generators in the basin, so the wind and current forces are simulated by constant forces on the centre of gravity of FPSO as the specified directions. A thin steel wire rope with light weight is connected to the FPSO, and the other side on the basin side is connected with the pre-calculated loads, and two pulleys are used to guide the line, the schematic plot in Fig.8, and the layout in the basin depicted in Fig.9. The constant wind and current forces are obtained through numerical simulation and compared with the actual wind and current. After the comparison, the wind and current forces are $1.0 \mathrm{MN}$ and $1.1 \mathrm{MN}$ respectively. 
Table 5 Parameters of the bottom lines after truncation

\begin{tabular}{|c|c|c|c|c|c|}
\hline Line & $\begin{array}{c}\text { Length } \\
(\mathrm{m})\end{array}$ & $\begin{array}{c}\text { Mass in } \\
\text { Water }(\mathrm{kg} / \mathrm{m})\end{array}$ & $\begin{array}{c}\text { EA } \\
(\mathrm{MN})\end{array}$ & $\begin{array}{c}\text { Diameter } \\
(\mathrm{mm})\end{array}$ & $\begin{array}{c}\text { Pretension } \\
(\mathrm{MN})\end{array}$ \\
\hline Line4,5,6,10,11,12 & 485 & 265.3 & 431 & 122 & 1.10 \\
\hline
\end{tabular}

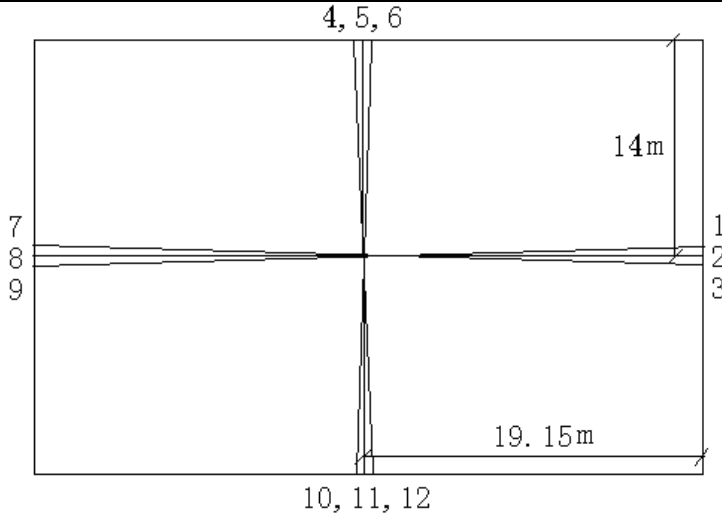

Fig. 6 Horizontal layout of the mooring lines
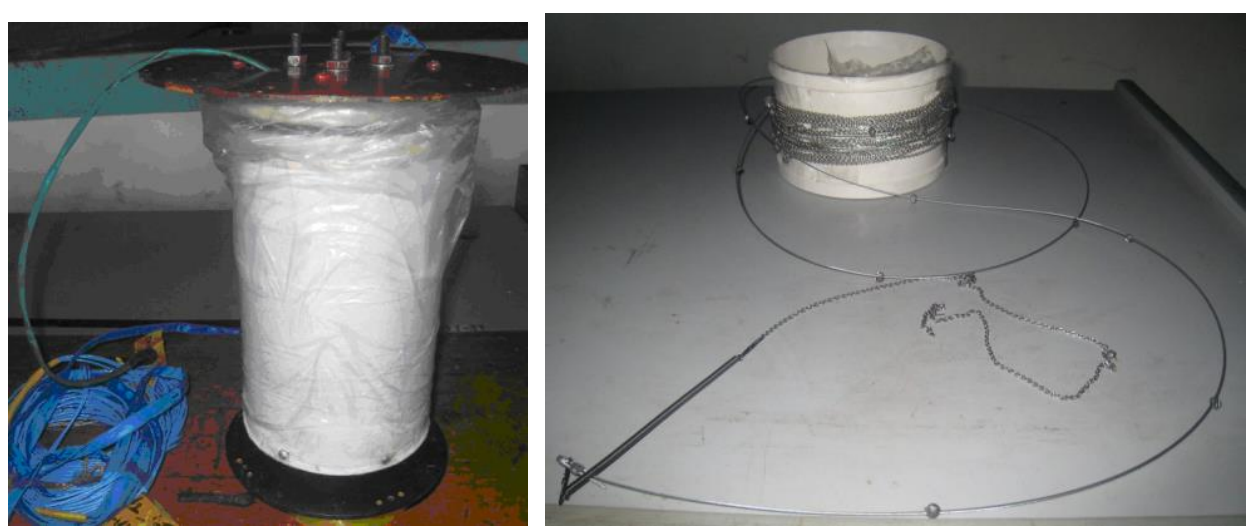

Fig. 7 Turret and mooring line models after calibration

Table 6 Parameters of the line model with adjustment

\begin{tabular}{|c|c|c|c|c|c|c|}
\hline Item & Line & $\begin{array}{l}\text { Length } \\
(\mathrm{m})\end{array}$ & $\begin{array}{c}\text { Mass in } \\
\text { Water }(\mathrm{g} / \mathrm{m})\end{array}$ & $\begin{array}{c}K \\
(\mathrm{~N} / \mathrm{mm})\end{array}$ & $\begin{array}{c}\text { Diameter } \\
(\mathrm{mm})\end{array}$ & $\begin{array}{c}\text { Pretension } \\
(\mathrm{MN})\end{array}$ \\
\hline \multirow{3}{*}{ Theory } & Top chain & 0.50 & 16.62 & 0.10 & 0.97 & \multirow{3}{*}{1.54} \\
\hline & Middle wire & 12.26 & 4.87 & 0.07 & 0.97 & \\
\hline & Bottom chain & 9.94 & 16.62 & 2.05 & 0.97 & \\
\hline \multirow{6}{*}{ Test } & Top chain & 0.65 & 16.23 & / & 0.80 & \multirow{6}{*}{1.55} \\
\hline & Middle wire & \multirow{4}{*}{12.38} & \multirow{4}{*}{4.08} & \multirow{4}{*}{0.07} & 1.10 & \\
\hline & spring & & & & 0.50 & \\
\hline & Connecting link & & & & I & \\
\hline & lead sealing & & & & l & \\
\hline & Bottom chain & 9.94 & 16.50 & / & 0.80 & \\
\hline Theory & $\begin{array}{c}\text { Truncated } \\
\text { bottom chain }\end{array}$ & 5.27 & 28.96 & 2.05 & 1.33 & 1.41 \\
\hline Test & $\begin{array}{c}\text { Truncated } \\
\text { bottom chain }\end{array}$ & 5.71 & 29.00 & / & 0.80 & 1.45 \\
\hline
\end{tabular}




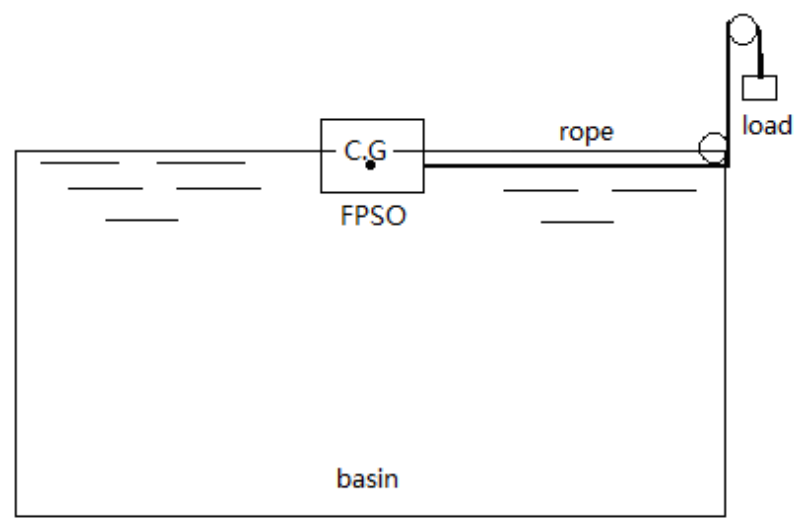

Fig. 8 Simulation of constant wind and current forces



Fig. 9 Model test of FPSO with wave, constant wind and current

\subsection{Comparison of the results}

At first, the static characteristics of the mooring system is discussed. The curves of the restoring forces of single line and horizontal mooring force on turret versus the offsets are plotted in Fig.10 and Fig.11 respectively, and the line of test-truc is the line with further horizontal truncation. When the displacement is more than $60 \mathrm{~m}$, the force of the horizontal truncated line is smaller than the un-truncated line. But since the truncated lines are lateral and not in the head sea, there is little influence on the whole mooring system, and the test results agree well with the numerical results in Fig.11, which verify the accuracy of the setup of the mooring system in the basin. At the same time, the catenary theory is certified to be able to simulate the static characteristics of mooring lines correctly.

The wave spectrum is simulated accurately by wave maker in the basin, and the comparison of the target and measured spectrum is in Fig.12.

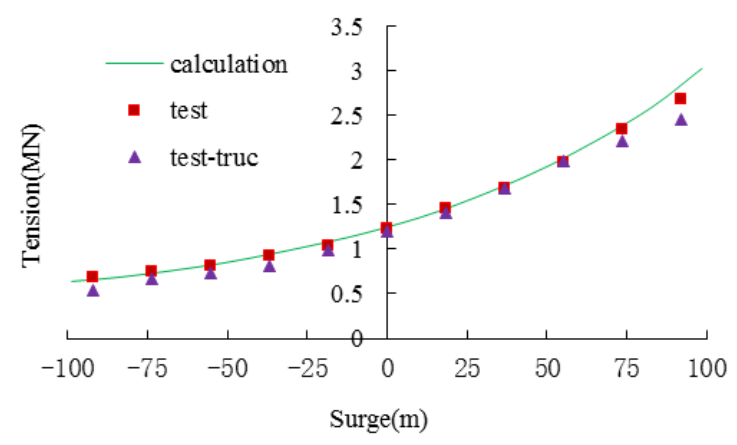

Fig. 10 Single line force-displacement

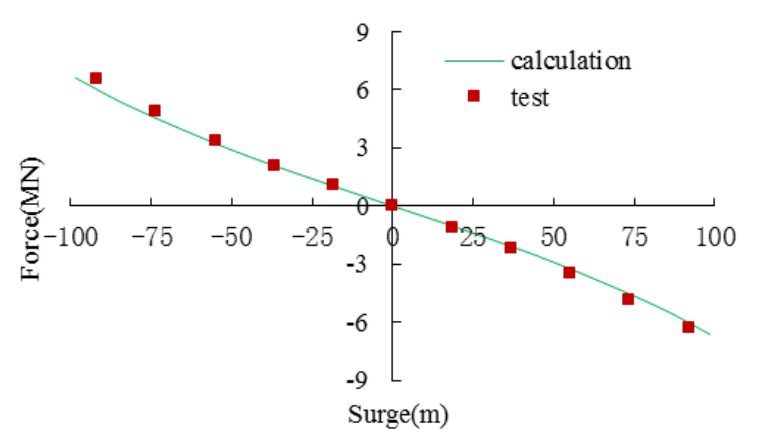

Fig. $11 \mathrm{X}$ force on turret - X displacement 




Fig. 12 Comparison of wave spectrum

Some representative results of the model tests are compared with the numerical simulations and given in table 7. At first, the FPSO motions agree well with each other for the quasi static and dynamic methods, but the mooring tensions of quasi static method are lower than those of the dynamic method. As described above, the dynamic fluid loadings are omitted in the quasi static method. It is found that it is more reliable to simulate the mooring lines with dynamic method.

In addition, the global response and mooring forces of FPSO in the model test are compared with those of the dynamic analysis. Most results can agree well with each other, but some difference always exist, such as the minimum surge in test is smaller than that of the numerical simulation, while the maximum tension of line 2 in test is higher than those of the calculation. The disparity is inevitable, and the reasons can be summarized as following:

(1) Since the anchor bases are used to fix the mooring lines at the basin bottom, errors might exist because of human factors, although they are set as designed.

(2) To satisfy the predetermined pretension, parts of the line lengths are adjusted slightly, which might result in the difference.

(3) The influence from the thin steel wire ropes to simulate the constant wind and current forces can not be avoided.

(4) Some other factors are leading to the following uncertainties such as measuring accuracy of instrumentations such as gauges, transducers and optical systems, deviation from wave modelling and measurement, human factors on the position control of model and anchor piles, and data processing.

Table 7 Comparison of results from quasi static, dynamic and model test

\begin{tabular}{|c|c|c|c|c|c|c|c|c|}
\hline \multirow{2}{*}{ Item } & case & $\begin{array}{c}\text { Surge } \\
(\mathrm{m})\end{array}$ & $\begin{array}{c}\text { Sway } \\
(\mathrm{m})\end{array}$ & $\begin{array}{c}\text { Roll } \\
(\mathrm{deg})\end{array}$ & $\begin{array}{c}\text { Yaw } \\
(\mathrm{deg})\end{array}$ & $\begin{array}{c}\text { Line2 } \\
(\mathrm{MN})\end{array}$ & $\begin{array}{c}\text { Line5 } \\
(\mathrm{MN})\end{array}$ & $\begin{array}{c}\text { Line8 } \\
(\mathrm{MN})\end{array}$ \\
\hline \multirow{4}{*}{ Max } & quasi static & -39.16 & 35.13 & 2.54 & 15.55 & 2.65 & 1.20 & 0.93 \\
\cline { 2 - 9 } & dynamic & -22.00 & 38.65 & 3.27 & 21.70 & 3.29 & 1.94 & 1.75 \\
\cline { 2 - 9 } & test & -26.36 & 31.32 & 5.49 & 27.44 & 3.54 & 1.64 & 1.62 \\
\hline \multirow{3}{*}{ Min } & quasi static & -87.90 & 7.30 & -3.19 & -0.28 & 1.70 & 0.93 & 0.65 \\
\cline { 2 - 9 } & dynamic & -86.09 & 6.91 & -3.87 & -3.84 & 0.93 & 0.41 & 0.31 \\
\cline { 2 - 9 } & test & -78.54 & 1.32 & -6.35 & 6.30 & 0.77 & 0.34 & 0.24 \\
\hline \multirow{3}{*}{ Mean } & quasi static & -60.91 & 19.44 & -0.14 & 7.18 & 2.08 & 1.06 & 0.78 \\
\cline { 2 - 9 } & dynamic & -50.00 & 21.59 & -0.14 & 7.44 & 1.97 & 1.05 & 0.81 \\
\hline
\end{tabular}




\begin{tabular}{|c|c|c|c|c|c|c|c|c|}
\hline & test & -47.44 & 15.49 & -0.51 & 17.5 & 1.75 & 1.05 & 0.86 \\
\hline \multirow{3}{*}{ RMS } & quasi static & 9.58 & 5.05 & 0.61 & 3.16 & 0.19 & 0.04 & 0.05 \\
\cline { 2 - 9 } & dynamic & 11.12 & 5.52 & 0.71 & 3.54 & 0.31 & 0.17 & 0.16 \\
\cline { 2 - 9 } & test & 11.49 & 3.46 & 1.81 & 2.07 & 0.32 & 0.15 & 0.18 \\
\hline
\end{tabular}

\section{Conclusions}

Based on above numerical simulation and model tests of the internal turret moored FPSO in different water depths, the following conclusions can be drawn.

1) Research on the hydrodynamic characteristics of a FPSO working in $914 \mathrm{~m}$ water depth is carried out through diffraction/radiation analysis in frequency domain and model tests in offshore basin. The RAOs are compared in detail, although the disparities exist, the results can agree well with each other with adding additional linear roll damping to the hydrodynamic model.

2) Coupled analysis to the FPSO and its mooring system in time domain is implemented, and both quasi static and dynamic analysis to the mooring lines are considered. It is proved that the results of dynamic analysis are more reliable than quasi static analysis.

3) Model test to the FPSO mooring system under hurricane environmental loads is carried out in HEU basin. Four anchor bases are used to fix the line models at the basin bottom. Special devices are designed to simulate the wind and current loads. Most of the results of model test are consistent with those of dynamic analysis, but some divergences still exist because of the objective factors during the test.

4) For the deepwater FPSO mooring system, coupling dynamic analysis in time domain is an effective method to catch the accurate characteristics of the whole system, and model test is an important and essential method to verify the numerical simulations, and they are complementary.

\section{ACKNOWLEDGMENTS}

The work presented here was supported by the National Natural Science Foundation of China (Grant Nos. 51509046, 51509045 and 51739001), and the Natural Science Foundation of Heilongjiang Province of China (Grant No. E2017029).

\section{REFERENCES}

[1] Paulling, JR, Webster, WC. 1986. A Consistent Large-Amplitude Analysis of the Coupled Response of a TLP and Tension System. In: Proceedings of the fifth International Offshore Mechanics and Arctic Engineering Symposium; Tokyo, Japan.

[2] Abyn, H, Islam, MR, Maimun, A, Mahmoudi, A, Kato, J. 2016. Experimental Study of Motions of Two Floating Offshore Structures in Waves. Brodogradnja. 67(2), 1-13. https://doi.org/10.21278/brod67201.

[3] Ormberg, H, Larsen, K. 1998. Coupled Analysis of Floater Motion and Mooring Dynamics for a TurretMoored Ship. Appl. Ocean Res. 20, 55-67.

[4] Tahar, A, Kim, MH. 2003. Hull/Mooring/Riser Coupled Dynamic Analysis and Sensitivity Study of a Tanker-Based FPSO. Appl. Ocean Res. 25(6), 367-382. https://doi.org/10.1016/j.apor.2003.02.001.

[5] Luo, Y, Baudic, S, Poranski, PF. 2004. Prediction of FPSO Responses-Model Tests Vs. Analysis. In: Proceeding of Offshore Technology Conference; Houston, Texas, USA. 
[6] Low, YM, Langley, RS. 2006. Time and Frequency Domain Coupled Analysis of Deepwater Floating Production Systems. Appl. Ocean Res. 28(6), 371-385. https://doi.org/10.1016/j.apor.2007.05.002.

[7] Low, YM, Langley, RS. 2008. A Hybrid Time/Frequency Domain Approach for Efficient Coupled Analysis of Vessel/Mooring/Riser Dynamics. Ocean Eng. 35(5-6), 433-446. https://doi.org/10.1016/j.oceaneng.2008.01.001.

[8] Tahar, A, Kim, MH. 2008. Coupled-Dynamic Analysis of Floating Structures with Polyester Mooring Lines. Ocean Eng. 35(17-18), 1676-1685. https://doi.org/10.1016/j.oceaneng.2008.09.004.

[9] Kolacio, I, Prpic-Orsic, J, Kurilic, K. 2010. Mooring Analysis for Semisubmersible Platform Scarabeo 7. Brodogradnja. 61(1), 34-41.

[10] Catipovic, I, Coric, V, Radanovic, J. 2011. An Improved Stiffness Model for Polyester Mooring Lines. Brodogradnja. 62(3), 235-248.

[11] Ma, G, Sun, L, Wang, H. 2014. Implementation of a Visco-Elastic Model into Slender Rod Theory for Deepwater Polyester Mooring Line. In: International Conference on Ocean, Offshore and Arctic Engineering; San Francisco, California. https://doi.org/10.1115/OMAE2014-23594.

[12] Zhang, F, Yang, J, Li, R, Chen, G. 2008. Coupling Effects for Cell-Truss SPAR Platform: Comparison of Frequency and Time-Domain Analyses with Model Tests. J. Hydrodyn. 20(4), 424-432. https://doi.org/10.1016/S1001-6058(08)60076-1.

[13] Jing, X, Webster, WC, Xu, Q, Lambrakos, K. 2011. Coupled Dynamic Modeling of a Moored Floating Platform with Risers. In: Proceedings of the ASME 2011 30th International Conference on Ocean, Offshore and Arctic Engineering; Rotterdam. ttps://doi.org/10.1115/OMAE2011-49553.

[14] Ma, S, Duan, WY, Han, XL. 2015. Dynamic Asynchronous Coupled Analysis and Experimental Study for a Turret Moored FPSO in Random Seas. J. Offshore Mech. Arct. 137(04130201-04130213). https://doi.org/10.1115/1.4030681.

[15] Yang, M, Teng, B, Ning, D, Shi, Z. 2012. Coupled Dynamic Analysis for Wave Interaction with a Truss SPAR and its Mooring Line/Riser System in Time Domain. Ocean Eng. 39, 72-87. https://doi.org/10.1016/j.oceaneng.2011.11.002.

[16] Ji, C, Cheng, Y, Yan, Q, Wang, G. 2016. Fully Coupled Dynamic Analysis of a FPSO and its MWA System with Mooring Lines and Risers. Appl. Ocean Res. 58, 71-82. https://doi.org/10.1016/j.apor.2016.03.008.

[17] Qiao, D, Li, B, Ou, J. 2012. Comparative Analysis on Coupling Effects between an Innovative Deep Draft Platform and Different Mooring Models. Brodogradnja. 63(4), 318-328.

[18] Qiao, D, Yan, J, Ou, J. 2014. Effects of Mooring Line with Buoys System on the Global Responses of a Semi-Submersible Platform. Brodogradnja. 65(1), 79-96.

[19] Newman, JN. 1974. Second-Order Slowly Varying Forces on Vessels in Irregular Waves. In: international symposium on the dynamics of marine vehicles and structures in waves; London.

[20] OCIMF. 1994. Prediction of Wind and Current Loads on VLCCs. In: Oil Companies International Marine Forum; London, UK.

[21] ITTC. 2005. Recommended Procedures and Guidelines - Floating Offshore Platform Experiments. In: Proceeding of 24th ITTC; Edinburgh\&Scotland, UK.

[22] Fan, T, Qiao, D, Ou, J. 2014. Dynamic Effects of Equivalent Truncated Mooring Systems for a SemiSubmersible Platform. Brodogradnja. 65(4), 35-51.

Submitted: 25.05.2017. Hongwei Wang, wanghongwei@hrbeu.edu.cn

Corresponding author: Gang Ma, magang@ @rbeu.edu.cn

Accepted: $\quad$ 28.08.2017. $\quad$ Liping Sun, sunliping@hrbeu.edu.cn

Kaiye Hu, hukaiye@ hrbeu.edu.cn

College of Shipbuilding Engineering, Harbin Engineering University,

Heilongjiang 150001, China. 